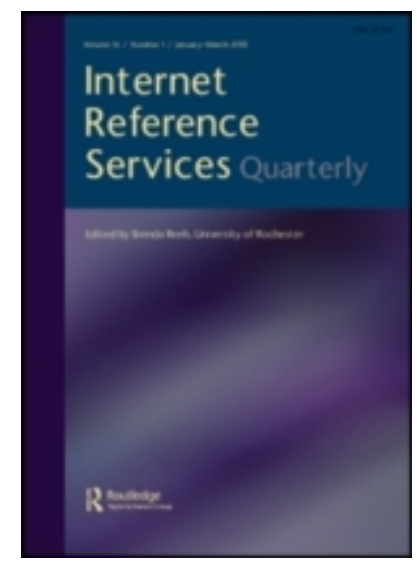

\title{
Overcoming Disruption in Special Collections Public Services
}

\begin{tabular}{|r|l|}
\hline Journal: & Internet Reference Services Quarterly \\
\hline Manuscript ID & WIRS-2021-0023 \\
\hline Manuscript Type: & Original Article \\
\hline Keywords: & public services, reference, renovation, equity, COVID-19, disruption \\
\hline \multicolumn{2}{|l}{} \\
\end{tabular}

\section{SCHOLARONE \\ Manuscripts}




\section{Overcoming Disruption in Special Collections Public Services}

Special collections and archives workers have unique experiences in providing service to their patron base while also working to overcome disruption and physical displacement. The disruption may take the form of a major renovation, a closure due to natural disaster, being forced out of a library space, budget cuts, or other operational issues. This article captures the experiences of twenty-eight staff members providing access services to their subset of users, in the form of interviews, in order to reflect upon how our profession connects with, provides services to, and places value on the relationships we cultivate with the public. We sought to gain insight from those who have experienced disruptions to their services in the past in order to apply this knowledge to the pandemic situation of 2020 and 2021, as well as those experiencing major disruptions in the future. The interview responses are a general representation of what staff may endure when embarking on a project that is a major disruption to service delivery. The experiences of the participants revealed a cyclical interconnectedness between the themes, indicating the complex nature of work involving human beings. The responses provide tangible recommendations to those planning for, beginning, or experiencing a disruption.

Keywords: disruption, public services, reference, renovation, equity, COVID-19 


\section{Introduction}

Working with the public in an archival or special collections library is, by its nature, an interpersonal experience. As many archives and special collections libraries have undergone renovations in the past several years, all have also undergone the universal experience of navigating operation during a pandemic. What do we do, as a profession, when our jobs become remote due to renovation, pandemic, or other major disruption, thereby interfering with the physically-based provision of services with which staff and researchers are most familiar? How have special collections and archives had to consider and later modify the delivery of public services in advance of, during, and in reflection of, a renovation or other disruption to the library space? What practices were enacted in order to accommodate a more remote form of service and how were the solutions to these challenges brought forward into post-renovation policies? How were practices and policies modified in reaction to COVID-19?

The purpose of this study is to interview special collections and archives workers who have had to overcome disruption in their work in order to provide service to their patron base. This disruption may take the form of a major renovation, a closure due to natural disaster, being forced out of their library space, budget cuts, or other operational disruptions. This article captures the experiences of twenty-eight staff members providing access services to their subset of users, in the form of interviews, in order to reflect upon how our profession connects with, provides services to, and places value on the relationships we cultivate with the public.

We sought to gain insight from those who have experienced disruptions to their services in the past in order to apply this knowledge to the pandemic situation of 2020 and 2021, as well as those experiencing major disruptions in the future. The top themes that arose from the majority of participant responses were staffing and labor, morale, and equity and safety. The experiences of the participants revealed a cyclical interconnectedness between the themes, 
indicating the complex nature of work involving human beings. The interview responses are a general representation of what archival and library staff may endure when embarking on a project that is a major disruption to service delivery. Additionally, the responses provide tangible recommendations to those planning for, beginning, or experiencing a disruption.

\section{Literature Review}

Thomas P. Wilsted writes convincingly in "Renovating Special Collections Facilities" about the need to preserve special collections as the most distinct and valuable parts of libraries' collections (2012). Wilsted's article helps to situate this moment in time, as the rapid growth of rare books, archival, and special collections in the mid-to-late twentieth century led to a need for renovation of such facilities in the early twenty-first century. Reasons for renovation may include outgrowing space, preservation requirements for the materials, the need for a larger reading room, security measures, improved climate control, or designated space for the digitization of materials.

Wilsted includes citations to practical guides on building or renovating archival spaces, including Pacifico and Wilsted's 2009 monograph Archives and Special Collections Facilities: Guidelines for Archivists, Librarians, Architects and Engineers, a book recommended by at least one participant in our study. Wilsted's article, paired with his other works on the practical specifications required for a special collections building upgrade, offer background on the architectural, design, and engineering needs of these specialized facilities. He also emphasizes the need for library staff to advocate for their own needs throughout the design and building process and for open and regular communication between library staff, administrators, architects, and other stakeholders in the project. 
There are a few recent and some slightly older articles which offer case studies on preparing for and undertaking a special collections renovation. These include Blackson and Stringfellow's 2021 article "It's Raining in the Archives" with an excellent literature review; Hatcher and Sciarini's 2017 presentation To Close, or Not to Close - that is the Question, explaining how they were able to remain open during the renovation of the massive Beinecke Rare Book and Manuscript Library; the much smaller move of the Marian Library within the University of Dayton Libraries system by Hoelscher and Burke Cahalan (2017); and Morrow's 1990 practical article which is dated but still relevant with its focus on the supreme importance of planning well in advance of a move (including shelf surveys, allocation of space, labeling, and so on).

Articles on special collections moves vary in approach based on the size of staff, size of collections, and funding available to the institution. Blackson and Stringfellow's (2021) takeaways included coordination amongst all stakeholders from administrators to facilities staff, outside vendors, and full and part time staff and the necessity of minute planning and flexibility for when things go awry.

An important point made by Hoelscher and Burke Cahalan (2017) is that a renovation can present an opportunity to change legacy practices that no longer make sense. "Framing these changes as a result of the move reduced pushback from staff and patrons alike" (p. 126). The same appears to be one of the positive results (if that term can apply) to changes and adaptations made by libraries during COVID-19, as our survey results will illustrate.

Hatcher and Sciarini (2017) explain how the Beinecke Library was able to maintain services in a temporary reading room during a full-scale renovation by forming a Renovation Committee two years before construction began. In addition to planning for staff moves, they 
also broke into a cross-departmental Stacks Committee to plan the cataloging, relocation, and safe housing of vast collections. They were able to hire movers to shift collections but also emphasized staff involvement in the move, spread out across multiple departments.

Lessons from the Beinecke Library renovation experience which are relevant to our study include learning to communicate clearly with users; "to plan even further ahead than you think you need to, and to consider suspending programs which will place heavy demands on materials and staff"; to "include all library staff into all stages of your project and...trust the judgement of the key staff members and the expertise of your vendors"; and "stay aware of your staff stress levels and help them build and maintain confidence in the value of their input" (Hatcher \& Sciarini, 2017, pp. 4-6).

Morrow’s (1990) article includes a discussion of staffing a move, whether with internal staff or external contractors and, most pertinent to our study, discusses how reference services were handled during the move, as well as special problems that arose during moves and how they could be avoided (hint, have an elevator mechanic available during the move!). The conclusion of Morrow's article is that many problems could be avoided "if building planners had consulted the users from the start” (Morrow, 1990, p. 430).

The above articles, monographs, and case studies and their bibliographies are great places to begin reviewing the literature in preparation for a renovation project or collections move. However, they do not tend to focus on the emotional toll that this work exacts on library workers.

Material related to the emotional labor involved in working in special collections public services is limited but one recent study makes this a priority, specifically surveying individuals who work in special collections public services in academic libraries regarding how additional 
workload beyond the scope of their job descriptions impacts them (Warren \& Scoulas, 2021).

Theme Four of Warren and Scoulas' study addresses feelings, which also emerged organically as a theme in our study. Warren and Scoulas also list several articles on low morale, overwork, work-work conflict, and understaffing.

There are excellent points in Warren and Scoulas's literature review about what causes burnout and how juggling multiple responsibilities can lead to increased burnout. Taking on unexpected, additional job duties during a renovation is a major issue, not directly addressed by Warren and Scoulas, but certainly related to their point. Furthermore, the potential for burnout can also be expected in other instances of upheaval, such as during COVID-19.

\section{Survey Methods}

The inquiry surveyed varying types of archival and special collections libraries staff on their experiences with overcoming disruption in their work. Parameters for participation in the study were defined as individuals who work with the public in a full-time position in Archives and/or Special Collections libraries. To qualify, their library must have undergone a renovation in the past five years (2015-2020), currently be undergoing a renovation, or have experienced another major operational disruption due to changes to their physical space such as a natural disaster, a major building malfunction (flooding, leaks, infestation, etc.), or having been forced out of their space.

The study took place between November 2020 and March 2021, during which the COVID-19 pandemic was still fully affecting libraries. Most participants were working from home during this time and were dealing immediately with the impacts of the pandemic. The timeline of the study was 1) call for participants in November 2020, 2) first email to participants, explaining the structure and purpose of the study, in late November 2020, 3) pre-survey Zoom 
calls with participants in December 2020 and January 2021, 4) send survey tool to participants, 5) post-survey Zoom calls with participants in January through March 2021.

While the survey itself (see Appendix A) is a written response tool consisting of about twenty questions, the authors sought to interact with participants on a more personal level by meeting with them over Zoom before and after they completed the survey. Each of these Zoom meetings was approximately thirty minutes in duration. The authors also asked four follow-up questions of every participant during the post-survey Zoom calls (see Appendix A) and took notes on participants' verbal responses.

Survey questions begin with a set of general questions about the participant's renovation or other disruption, followed by questions regarding reading room management and reference email management. The survey continues with questions about services during COVID-19, and specifically, if there was crossover between the pandemic period and the other identified disruption. Due to the tangential nature of instruction duties and public services, we also asked participants about changes that occurred to instruction programs, if any.

The final section asks questions about strain on staff and patrons and how to manage these issues. The authors asked a set of questions in the follow-up interview to mainly focus on size of staff and collections. We also left room for participants to add anything they felt we missed in our set of survey questions.

After interviewing participants and reading their written contributions, some major themes emerged. Authors coded the written interviews into one of twelve categories (see Appendix B). The codes were tallied for each interview individually and as a set (see Table 1). This data then influenced the authors' direction in their writing. 


\section{Recruitment}

The authors attempted to broadcast the survey as widely as possible. The call for participation was posted on listservs associated with the rare books, archives, and special collections professions. Listservs emailed include Exlibris, Rare Books and Manuscripts Section (RBMS) of the Association of College and Research Libraries (ACRL), the Teaching with Primary Sources (TPS) Collective of RBMS, the Society of American Archivists (SAA), the Philadelphia Area Consortium of Special Collections Libraries (PASCAL), and We Here, a community for BIPOC folks in library and information science professions and educational programs. Additionally, we posted to the more general Reference \& User Services Association (RUSA) of ACRL. Both authors brainstormed institutions known to have undergone a renovation in the past five years.

Second only to participation parameters, gathering a sample of experiences from a diverse pool of participants was a top concern. Initially, the authors sought to survey twenty individuals from a diverse array of institutions in equal amounts: small and large, Historically Black Colleges and Universities (HBCUs) and predominantly white institutions (PWIs), public and private, university or college-affiliated and independent. Due to a high response rate to the call for participation, we increased the capacity of the study to include up to thirty participants. While thirty people initially agreed to participate, the final total was twenty-eight participants due to attrition.

Institutions represented in the final results are eleven private colleges or universities, ten public colleges or universities, three Ivy+ universities, one HBCU, one public library, one independent private library, and one preparatory school library. We have made our best efforts to retain the anonymity of all participants and will only refer to each individual by an arbitrarily assigned number and the general size and type of institution they represent. 


\section{Biases incurred}

The authors sent specific emails to libraries and special collections they knew had recently, currently, or were preparing to undergo renovation. Some institutions may have been unintentionally left out of this group due to the authors not knowing about their history with renovation or other disruption.

While the authors advertised the survey in a number of places, some forums were specifically intended for those that pay for access (i.e. ALA, RBMS, and SAA affiliations). Additionally, the authors may have left out some groups that were not reached by the stated recruiting methods, such as religious institutions or others. As a result, those who are unable to take on the financial burden of professional affiliation or, alternatively, have differing forums unknown to the authors may have been left out of the survey and subsequently were unable to share their experiences.

\section{Survey Results}

\section{Overview}

The survey results revealed that the most common themes between all participants were topics related to staffing, external communication, time, morale, and equity. The staffing theme discusses who did specific types of work during the disruption (i.e. students, part-time staff, fulltime staff, outside contractors, and others) and also includes discussion of specific staff duties. The external communication theme discusses communication with researchers, library users and community members, and also includes reference work. The time theme discusses the timeline of disruption or any time-related challenges. The morale theme discusses the morale, emotional, and mental health issues among staff and/or patrons. The equity theme discusses issues of equity 
and/or inequality at a structural or interpersonal level. Many staff also discussed their feelings of safety or lack thereof which was coded under the theme of equity.

After reviewing the interviews post-coding, the authors identified the topic of time to be too general and omitted it from the survey results.

Table 1: Tallied and combined results in numerical order

\begin{tabular}{|l|l|}
\hline Theme & Total \\
\hline Staffing & 368 \\
\hline External communication & 280 \\
\hline Time & 196 \\
\hline Morale & 174 \\
\hline Equity & 165 \\
\hline Technology & 158 \\
\hline Recommendations & 122 \\
\hline Administration & 117 \\
\hline Internal communication & 103 \\
\hline Security & 46 \\
\hline Funding & 37 \\
\hline Random & 32 \\
\hline
\end{tabular}


Out of the twenty-eight respondents, twenty-five identified undergoing a renovation as the source of their major disruption. One respondent experienced a fire and three experienced flooding. Some libraries experienced multiple disruptions including concurrent renovations and floods, issues with service facilities like an elevator, or cyber attacks. One respondent discussed a forced removal from a portion of their archival storage. Considering the timely fact that the world experienced the pandemic in 2020 and 2021, all respondents mentioned their response in providing public services.

The survey questions intended to capture the quantitative data related to the processes of daily professional life, however it became clear once interviewing participants that their responses were intimately entangled with more qualitative-type data. The manner in which the cohort of participants responded to the survey in this way was overwhelming and speaks to the various ways major disruptions impact the staff and personnel of organizations.

\section{Staffing and Labor}

\section{Overview}

Among the twenty-eight survey responses, issues of staffing arose approximately 368 times, for an average of about thirteen mentions of staffing per participant. Staffing and labor issues were by far the largest themes to emerge from this study, which comes as no surprise. Staffing is at the heart of all library work and most issues of service are intrinsically tied to the humans who provide this labor.

Of course, how a rare books or special collections library is staffed is contingent on funding and the size of the institution. Staffing ranged from, on the low end, one librarian who must devote only about 35 percent of their work time to special collections at a small private institution to, on the high end, 110 full time employees at a large Ivy+ institution. The way 
libraries apportion public services and instruction duties also varies widely with job descriptions often including reference work, public desk shifts, instruction, curatorial, and archivist duties among the roles of a "public services" employee.

\section{Defining Staff}

After the initial survey of respondents, we added a question about staff size as a follow-up during the post-survey Zoom calls. One of the most complicated questions that arose was "what is a staff member?" Archives and special collections libraries are staffed by full-time and part-time employees, faculty and staff employees, paid and unpaid interns, visiting fellows, and student employees. Oftentimes duties blur from one individual to another and department structures are different for each institution, making direct comparison impossible. Some of the themes that arose were hidden labor, equity of employment between full and part-time and between technical and public services workers, challenges of staffing during a pandemic, and size of staff relative to the exhausting work of moving for renovation.

Many institutions within university or college systems employ student labor. Of those surveyed, seventeen out of twenty-eight respondents (approximately sixty percent) explicitly stated that they utilize student labor, even though this was not amongst our specific questions. The actual figure might be higher due to lack of specific questions on this subject. In some cases, student labor was curtailed during the pandemic due to budget cuts as well as safety concerns for temporary employees. As Participant 3 pointed out in the wrap-up Zoom call, they employed fewer students during the pandemic than their usual eight to twelve students. They anticipated needing to hire and train a new workforce once regular operations resumed. Participant 18 at a large public university also had to cut student hours due to the pandemic, down to fifteen hours 
of scanning and seventeen hours of technical services from a typical 80-100 hours of student labor per week.

In response to the question of carrying forward lessons from a renovation or other disruption into the pandemic, Participant 27 from a large private institution wrote:

Yes, albeit tangentially. During the disruption, we had to develop projects for student employees so they could continue to work and earn income. This involved transitioning from physical archival processing tasks (e.g., labeling folders) to becoming proficient with the staff user interface of our catalog in order to update records. We saw that we were able to hand off some time-consuming research requests to them. We now trust our student employees to assist with reference services, although it is still only professional staff who communicate directly with patrons.

\section{Challenges}

When coding the surveys, the authors noticed that commentary centered on the challenges of staffing, especially during a disruption or unexpected large-scale event.

Logistical complications. Some challenges linked to serving special collections materials to the public are the security needs and the logistical issues related to the handling of rare, valuable, or unique physical collections. These issues were only exacerbated by pandemic circumstances. As Participant 10 from a large public institution described, staffing logistics brought new challenges during the COVID-19:

[The institution] changed from walk-in access to appointment-access only... Appointments have to be made 5 days in advance, and materials have to be requested 5 days in advance too. Previously we had procedures for users to request materials and have them immediately paged by student workers and delivered to the reading room; for now we do not offer that flexibility. That's due both to the necessity of quarantining items for 5 days after they're handled by a user, and the logistics of moving materials between the stacks and the reading room. The librarian supervising the reading room 
might be the only [library] staff member present in the building at any one time; they can't leave the reading room to page material from the stacks and bring it up.

Budget cuts. Budget cuts during COVID-19 were another major challenge. Participant 26 from a large public institution wrote:

Additionally, our budget was cut on March 16 $6^{\text {th }}$ [2020] for our part-time employees. There was a lot of confusion about Federal Work Study workers as well. There were no part timers working for us from March $16^{\text {th }}$ through the end of April; however, there was one unpaid intern that carried on remotely during that time to finish their required hours. During the summer semester, FWS students could return and do remote work but our normal budget was not reinstated. Part time workers were allowed to return to work in August in-person. The biggest challenge were the researchers that wanted a lot of research done physically. Between March and June, this was not feasible.

Layoffs and retirements. Participant 21 from a small private institution added in their wrap-up Zoom meeting that they have experienced a lot of staff turnover during their renovation and pandemic. The pandemic prompted early retirement offers at their institution. Some people were worried about their health and that was an impetus to retire as well.

As Participant 21 related: When you lose people you also lose their knowledge about the institution, the history, where to find things. While also experiencing that loss, you also face uncertainty. When are you going to get new people? In the meantime, do you pause certain work? Is pausing certain work even possible? Furthermore, the pandemic has fundamentally shifted what we do in special collections libraries. We have had to put some things on hold. How long can those things stay on hold? There are a lot of entangled issues here.

Participant 9 also had a retirement in their department and a new dean during the renovation process. Participant 11 had their department head retire two weeks before their move happened and the position was not replaced for a year. Participant 8 had a number of high level staff changes during the pandemic, right as they were returning to campus. They wrote: 
There were many outside challenges; at the end of June before our return to the building, our Director of 20 years retired. There was also a change in University President, Vice President, and Provost during this time, so there were many adjustments on many levels throughout this entire process.

Participant 21 had a retirement affect their workflow during the pandemic:

Between the previous reference archivist retiring and the new archivist starting, we developed a hefty reference backlog, though we had staff responding in shorter and more simplified ways.

Participant 13, as the sole person in their department, was furloughed for thirty hours per week for six weeks during the summer 2020 due to the pandemic. Participant 27 also experienced furloughs, combined with rumors and miscommunication, during the pandemic:

The pandemic triggered a significant series of lay-offs at our university and that, too, contributed to rumors that reference staff had been terminated (three, in fact, were furloughed for four months but were brought back on board in time for the beginning of the fall semester). We have had to continuously reinforce in our messaging that we are “open for business" even though campus activities are severely limited. Overall, the messaging surrounding the closure could have been better crafted to avoid misperceptions.

Invisible labor. Work during renovations and the pandemic was often overwhelming and staff frequently took on an excess of hidden work in order to provide services to their communities at the behest and/or expectation of administrators. Participant 28 from a small private institution wrote:

We continued reference by email and phone, and during the building closure we did a lot more research and scanning for patrons than we normally do to give patrons reasonable access ... We went overboard in helping patrons get to materials in alternate formats (digital, other editions available elsewhere, etc.), and we spent much more time doing research for patrons. Normally we say we provide a reference and not a research service, 
and invite local patrons (students, faculty, administration, local community) to come in to do their own research after we have located the material they want.

Even when physical spaces are closed, this does not mean that staff are not applying labor for their users. One concern is that this labor might become hidden as some services go online. Participant 27 from a large private institution wrote:

One topic we have been discussing is the language surrounding 'being closed' and 'being open.' Although no one can visit our reading room, the libraries and archives aren't really closed if the people who work under the administrative unit called Libraries and Archives are as busy as ever. We are demonstrating that what we call 'a library' does not require a central space, but it does require professionally trained and/or supervised staff who can connect patrons with information sources. How we employ language to convey our role in the university community is an ongoing exploration.

Staff have been overburdened by the dual challenges of renovations and the pandemic. However, nearly everyone surveyed felt that they had risen to the challenge. The fact that most were successful in spite of global catastrophe, points to the amount of invisible labor occurring in libraries.

Labor and morale. Some comments blur the line between the themes of morale and labor, especially when the subject is emotional labor. Participant 3 from a small private institution wrote:

Emotional labor has also been a challenge. Many patrons are frustrated at the level of access, and having to assure them continually that we want to help has been difficult. It can also be extremely frustrating for staff to hear, in response to a cheerful "let me know how else I can help," "open the library!” In almost all cases, the staff member in question does not have the power to make that decision (indeed, in our situation, even our library director could not unilaterally do so - we need a campus decision to allow visitors again). Furthermore, the ultimate thrust of this statement is "my research matters more than your life," which is never an easy thing to hear. There are no emergencies in special collections, and very few research emergencies (contagious disease research excepted). 
To continually hear from patrons that not only our labor, but also our lives, are not important to them is draining and challenging.

Renovation staffing. In terms of renovation challenges, staffing was a recurring theme. One participant is the sole special collections staff member at a preparatory school. They were able to hire one additional part-time employee to help with the move which proved invaluable. Other institutions also hired additional staff to help with the monumental task of moving collections or to assist with staffing during the disruption. Participant 11 from a public library's special collections unit was relieved that an adult services librarian was assigned to assist at their temporary location while the building underwent renovation.

Participant 23 from a large public institution wrote that they did all of the move themselves, with the assistance of students:

The move was done on a shoestring budget and the [institution's] staff and student workers, as well as other library staff and student workers, moved the entire collection and what furniture and office materials they could. Faculties did the rest of the moving and installed shelving. Given all the limitations, we did the best we could and the move was successfully implemented.

\section{Positive Outcomes}

One positive theme throughout the comments on staffing was that challenges were eased by having affirming and supportive supervisors and administration. Participant 12 from a large private institution wrote about COVID-19 equity issues, safety, morale, and general ideas the profession should embrace:

The most important thing is that those of my staff coming in feel safe. [Our location] was a crazy and sad and difficult place immediately in March and for a long time and the stresses of that haven't gone, and won't for a long time. We aren't saving babies. We have embraced the idea that there is no such thing as a bibliographic emergency.... 
Another time when labor challenges were outweighed by the positive was when people worked together as a team in the face of obstacles. Notable in this account is the fact that senior management helped with physical labor, which boosted morale and contributed to a teamwork environment. According to respondent 19 from a large Ivy+ institution:

We were able to page/return items from the [library building] once a day in a 2-hour window, although at various times certain collection items were unavailable due to building construction. We employed an all-hands approach to paging and returns and all [library] staff (including senior management) were required to take a shift in the paging convoy. While this caused some grumbling initially, it proved to be an incredible bonding and morale building experience for the staff. Staff were able to come together and work together in ways that the renovation had otherwise disrupted (with staff scattered across buildings).

\section{Morale}

\section{Overview}

Among the twenty-eight survey responses, the issue of morale arose approximately 280 times, for an average of about ten mentions of morale per participant. As stated previously, the idea of a qualitative survey was not the original intention of inquiry, however, all participants brought up their emotions, indicating that their sense of professional well-being, both positive and negative, was directly tied to their experiences with disruption.

The idea of morale, "the degree to which an employee harbors negative feelings about [their] workplace or dissatisfaction with aspects of the work or workplace," (Kendrick, 2017, p. 869) is an individualistic, subjective sentiment that, interestingly, can also be ascribed to a larger group (Kendrick, 2020, p. 17). The specifics of the negative feelings differ between individuals as "identity is fluid and dynamic and affected by historical and social changes ... [intersecting at] various aspects ... such as race, class, and gender" (Kezar \& Lester, 2010, p. 165) but the general 
sentiment of dissatisfaction can spread throughout a group. The realities and struggles of the profession have been detailed in the complimentary articles on vocational awe (Ettarh, 2018) and vocational melancholy (Smith, 2020). Do library workers face disappointment and burnout upon the realization that the library, as an institution, does not provide as holistic of support to workers, patrons, and communities as popular culture may have us believe? Does the idea that libraries are sacred spaces permeate beyond popular culture into the workplace, discreetly encouraging staff to dedicate their whole selves to their work despite the inability to receive reciprocal appreciation in return?

The combination of these concerns are amplified when also adding in a major event (or two) that disrupts the structure and routine of daily life. Participants discussed their specific difficulties that resulted in, or were related to, grief and trauma. Some participants attempted to rebound from the stress and morale concerns by instilling joy in their work and colleagues, and even more, many were able to discuss the eventual, positive outcomes.

\section{Difficulties, Grief, and Trauma}

Renovations. Fourteen respondents noted that the specific, major disruption they experienced created feelings of trauma that negatively impacted their morale. Most frequently, the drastic changes from a renovation left them feeling lost, unheard, and their contributions unacknowledged. Notably, participants who underwent a building renovation felt particularly affected. Though done with some humor, Participant 6 discussed the striking emotional impact their library renovation had on staff:

Library administration needs to acknowledge and plan to mitigate the extreme emotional stress of a renovation on a library staff. We watched a place that we love - a place that we spend time in every day and that we have devoted our careers to-be dismantled before our very eyes. We watched the books and manuscripts we spend so much time and 
energy providing access to be packed up and sent away. Our normal jobs disintegrated into thin air and we were assigned new duties - many of which we did not like or did not feel qualified to do. Teaching librarians found themselves creating complex spreadsheets for temporary vault storage. Catalogers found themselves packing boxes of office equipment. We were not just fish out of water; we were fish yanked out of a nice happy warm pond that we love, hurled onto the dry land, given tubas and asked to play in an oompah band. And then yelled at when we were out of tune and our rhythm sucked. Respondent 17 discussed their decreased morale after placing multiple, unheard renovation requests:

It's deflating not to be heard, much less even acknowledged. All of us are grieving. Grieving the downsizing of our print collections, downsizing of workspaces, and we feel diminished as a campus entity. Our morale flagged terribly ... when we went back to work and saw what we were allotted for space and how poor the furnishings were for our needs. We are still feeling low ... We feel minimized and unappreciated."

One participant who wished to remain completely anonymous wrote about a top-down staffing approach to a renovation that had negative impacts on the equity of the decision-making process:

We had to fight for every inch that we got as far as reducing any services, and everything had to be approved at the highest levels ... We had to fight extremely hard to get the short closure that we had. The [top-level administrator] originally expected us to reopen much sooner, even though construction on our temporary RR was not yet completed! All in all, it was a nightmare.

COVID-19 specific. Furthermore, the COVID-19 pandemic was an intense and sometimes traumatic experience for many. The world, our lives, and our work cultures that were so familiar were, all at once, unrecognizable. Adapting to that change has presented difficulties and many participants discussed this in their surveys. Participants discussed the safety of their working conditions, or lack thereof; researchers who were understanding of the required changes to the service model and researchers who refused to follow safety guidelines; and the unfortunate repercussions of the illness on family and colleagues. 
Participants 6 and 21 discussed the strain on their physical and psychological health. Participant 6 stated:

Working onsite is also stressful because we are in a constant state of danger from the pandemic. We have been able so far to control our environment and spaces and only work when we feel safe to do so, but it is still taxing. Just getting to our work stations through all the pandemic checkpoints is exhausting. Working with a mask is exhausting. The fact that all our collections are scattered and getting anything is a major challenge makes it seem like every single task is a mountain to climb. Things that were once fairly effortless (request a book, run up to the stack to grab it, hand it to a patron) can now take days or even weeks. Every time we deliver something to a patron it feels like a small victory.

Participant 21 stated:

Continuing to work at the same level, with the same expectations and load of work, during this has been utterly exhausting. I had my first vacation in a year during the end of December and all I did was sleep. I'm still exhausted and I'm not sure how I'm going to manage. (And I don't have children or others that need my constant care, unlike many other folks.)

Some participants discussed the fact that decisions about staffing were made by administrators rather than library staff, which contributed to the stress of staff having to make hard decisions for themselves that may counter what directives they received. Should they put their health at risk, or stay home and potentially not receive a paycheck? How might one accept the increased work responsibilities while also transitioning to being a main caregiver to children, parents, family, or friends? How does one provide caregiving, but also be expected to teach or provide synchronous learning experiences from the same location? Participant 15 noted that balancing work and grief was essentially impossible for the team and the experience was difficult to process. The expectations from administration were disconnected as staff were simultaneously being 
encouraged to take care of themselves and yet were still required to be present and attentive at work. Participant 21 also pondered the implications of COVID-19 on research:

I think researchers appreciate getting scans of materials they want, but there is a loss in them not being able to see materials in context themselves - what serendipitous moments are lost in this research? There is missing context, even with reasonably good finding aids. Likewise, our bibliographical description is minimal and lacking in subject analysis and detail, so it's easy to conduct a known-item search, but nearly impossible to find books with specific material, provenancial, or subject elements (e.g., annotations, hand-colored illustrations, works in English by Black women, etc.).

\section{Instilling joy}

Despite the stressors that come with major disruptions, our participants made it clear that instilling joy through the grief was necessary for their overall well-being and recovery.

Participant 12 stated the importance of being an administrator who reminds their staff that what they are experiencing is not normal and that they can see how their staff is doing the best they can. They hosted a well-received staff conversation to focus on what people were proud of and what was hard during their major disruption. This discussion helped the staff reorient their experiences and appreciate some things they formerly took for granted. Similarly, Participant 18 encouraged their staff to not "stress out about the number of emails" they have and that though taking longer to answer reference questions may be a deviation from the norm, if doing so helps people decrease their stress levels, then it is well worth it.

Participant 15 shared that a joyful moment came from celebrating a team member's birthday. Virtual parties accompanied the virtual landscape of the pandemic, complete with gifts of festive cupcakes and dancing. Another participant stated how beautiful, moving, and emotionally beneficial it was to have a colleague play the viola da gamba in a stairwell over the course of a few days. Participant 19 noted that coming together over food and drink occurred 
after their building officially closed the doors for a renovation. People had been emotional about closing prior to the gathering, as they felt wedded to the physical space itself. There was a sense of catharsis and release in celebrating the momentous next step the staff and building were on the precipice of surmounting.

Overall, caretaking for one another was what most participants mentioned as giving the biggest morale boost, whether it be from colleagues or researchers. It signaled that people were receptive to the needs of others and spoke to the willingness of others in attempting to understand the context of an individual's experience (Kezar \& Lester, 2010).

\section{Positive Outcomes}

Survey participants were able to specify positive takeaways from their experiences despite the stress of the situations they encountered. The most common sentiment was how proud people were to have been able to make it through, to pull together as a staff, to maintain some semblance of normality through their experience, or alternatively, to break out of old habits that did not serve them or their community any longer.

Participant 19 noted that their staff felt good about their building's renovation as it was driven by the goal and desire to make their space more accessible and inclusive. Some of the changes included installing ramps, an elevator, and ADA furnishings, to change their lobby displays of dead, white male writers, and to eliminate the security guard at the main entrance. With everyone on board, including the architect and related staff who were "intentional about getting staff input all the way through," it made the overarching experience a positive one.

In relation to the safety concerns the pandemic created, the morale of some participants increased due to the seriousness of the situation as acknowledged by colleagues and administrators. 
Participant 4 wrote, "I'm very proud of the level of service our staff was able to provide, while maintaining safety and health as our primary focus." Similarly, Participant 6 wrote, "Honestly, I cannot think of any way we could have handled this better. We are providing great service, people are happy, and every member of our staff is healthy — which is really the only thing that matters." Participant 18 was particularly impressed with their staff's morale:

I am very proud of the work that I and those I supervise have done this year. In the first few months after returning to the office after COVID WFH, we produced $4 \mathrm{x}$ the average number of annual digital scans. We have updated policies and procedures, had video meetings with researchers from across the globe, and provided physical access for people when necessary. We found ourselves in a situation where there were no expectations, could be no reasonable expectations, and have exceeded our wildest dreams. If anything, institutional loyalty is higher than it has ever been, just because we did our best and succeeded.

While not all participants had a positive experience during the pandemic, their final word on the subject attempted to find a constructive summary. Participant 20 and fellow staff felt like the pandemic exposed a lot of their work. When things were in-person, their lack of providing digital access to collections was not as apparent, they could "hide" behind excuses. When COVID-19 made everything virtual, it became apparent that they did not have the access to their collections that they, and, more importantly, their community, needed.

As Participant 23 noted, the whole world experienced trauma during the pandemic and that it is important to remember to be gentle to oneself and with one another. This reminder aligns with current professional discussions of embracing a framework of care through radical empathy (Caswell \& Cifor, 2016). Participant 22 echoed this in stating "During our renovationrelated closure, we had learned to be patient with ourselves and to be clear about limitations and boundaries, and this carried forward into the pandemic." Several respondents commented that 
filling out the survey was in itself a cathartic exercise and a helpful form of reflection on the challenges of their major disruption of the past several years.

\section{Equity and Safety}

\section{Overview}

Among the twenty-eight survey responses, issues of equity arose approximately 165 times, for an average of about six mentions of staffing per participant. While this was not one of the highest ranking themes, we found it notable, especially since equity was not an area of inquiry included in the survey or the wrap-up questions. While we set out to learn how people applied lessons from one form of disruption to another form of disruption, we found ourselves also contemplating larger issues in the field and our society such as racism, sexism, and even basic health and safety. As a theme that arose organically, we wanted to bring special attention to it, especially in light of the current workplace climate with its emphasis on DEI initiatives.

We defined this category as issues of equity and/or inequality at a structural or interpersonal level. We also determined that equity could be defined in this case to include issues of staff safety, since the pandemic brought to light inequities concerning exposure to a deadly disease among staff. Two participants also raised concerns about workplace safety during their renovations.

\section{Challenges}

Sexism. One of the most recent demographic surveys conducted in the field of rare books and special collections was the 2015 Rare Books and Manuscripts Section (RBMS) survey summarized in Healey and Nykanen's (2016) “Channeling Janus: Past, Present, and Future in the RBMS Membership Survey". At that time, the number of men in the field had dropped to just 
twenty-three percent (from thirty-six percent at the time of the last survey, 18 years prior). Even though women accounted for seventy-seven percent of the field, they were still underrepresented in administrative roles and drew smaller salaries than men (Healey \& Nykanen, 2016). This disparity was at play in the results of our study. For some participants, the experience of undertaking a renovation was punctuated by negative experiences with gender dynamics in the workplace. Participant 28 from a small private institution and Participant 13 from a preparatory school both perceived that their opinions were not taken seriously by male renovation contractors, at least in part, due to sexism against women. In the case of Participant 13, the architect and the director were both white men and the Participant felt locked out of their toplevel decision-making.

Participant 28 had both positive and negative renovation experiences which they were able to compare directly, specifying the role sexism played in their negative renovation experience:

We had a wonderful experience with the roof and skylight replacement because the contractor assigned us a project liaison who listened to us and was our advocate. He was willing to listen to our needs and why, and valued our expertise. We had a dreadful experience with the HVAC contractor because there was no liaison, and our needs and expertise were dismissed constantly. I had to be willing to push, and push hard, to get what we needed, and I was willing to play the "do you know how much mold remediation for this building will cost" card. It shouldn't have been that hard, even with advance planning, but the planning and advanced requests for fans and to keep the sheet wall up for the duration were ignored. I got the distinct impression the HVAC contractors thought we knew nothing about HVAC systems or heat and humidity levels or anything else; we were "just" librarians, and mostly female. In spite of our best efforts and planning, the HVAC installation was a fiasco from a physical plant viewpoint. 
COVID-19 specific. In some cases, participants noted that the transition to remote service during COVID-19 led to more equitable access for researchers via digital surrogates and online interactions. Others found that the new rules and regulations hindered researchers' ability to easily navigate special collections spaces. For Participant 10 from a large state institution, the pandemic restrictions had a negative impact on ease of access to their space:

I think we're providing the best services possible under the circumstances, but the circumstances don't allow a level of service anywhere near as convenient and welcoming as before. Users have to be REALLY motivated to use Special Collections now.

On the other hand, Participant 8 as well as Participant 27 found the virtual options employed during the pandemic were helpful. Participant 27 from a large private institution said that it helped cut down on the divide between those who could afford to visit them in a major metropolitan area and those who could not:

[In their location] it is prohibitively expensive for researchers outside the Metro area to make research appointments with us due to the exorbitant costs of lodging. Now that no one can visit us in person, everyone is "that researcher" who would dearly love to come to the reading room but has no funding - institutional or personal - to make the visit. It is equalizing.

Participant 8 at a small public institution said virtual options proved helpful when engaging with students:

I will absolutely keep the virtual consultation and student research appointments as an option in the future, as these were a way to connect with students who may not have been comfortable visiting the archive. I feel like treating the students like actual researchers, who need specific sources for their specific research questions, made them more comfortable in using these materials and more confident in the presence of digitized collections.

Most participants provided an overview of their institutions COVID-19 safety plans in answer to the questions in sections four and five of the survey. Most felt that their safety was taken into 
consideration. Some of the methods implemented include minimizing in-person contact with researchers, making accommodations for staff with underlying conditions, requiring reading room appointments, requiring health screenings, and staggering staff shifts in the building. Participant 16 from a large public institution wrote about the specific COVID-19 protocols they implemented to keep staff and visitors safe:

Staff are asked to work from home when possible and are not permitted to work on-site 5 days/week. Staff must submit a building log indicating the hours/locations worked on-site to assist with contact tracing. Special protocols have been employed during the pandemic for all researchers and staff - masks, temperature checks, extra cleaning protocols, capacities, quarantining of collections after use, etc.

Influence of administration. In cases where participants reported feeling unfairly treated, unsafe, or unsupported, the origin of those circumstances tended to trickle down from administrative policy and communications. These reports align with positionality theory, and perhaps reflect the field's need to embrace and reflect "our diverse, complex, and globalized world" (Kezar \& Lester, 2010, p. 165). Positive morale for staff in the workplace depends "on organizational factors such as the ability to progress, workload, respect, and funding for new hires," but "feeling supported by and connected with an immediate boss [is] critical for high morale" (Kezar \& Lester, 2010, p. 165).

As an example, pressure from administration led to inequality in staffing for Participant 15 from a large private institution. This participant felt that staff safety was less of a priority, with the burden of risk being placed on three people:

A lot of promises of assistance were made to help [their department] with reference and reading room service, but while also messaging to other staff that they did not have to return to campus. Without anyone willing to enter the building, and essentially no staff who are not faculty equivalent, the burden has fallen on three people. Admin continues to pressure a full forty hours of availability for researchers, which would essentially 
eliminate the remote reference program. In many instances we have been asked to develop policies based on [institution] level policies that did not exist yet (like developing a visitor access policy only knowing that [the institution] would publish one eventually). There is a [library reopening committee] that has been meeting since last Summer, but it is all senior management staff, who do not work on site or at service points.

Furthermore, when staff are working under extenuating circumstances, lack of clear policy from administration can lead to unforeseen issues in terms of providing equitable service to one's patron-base. Participant 3 from a small private institution wrote, regarding service during their renovation closure:

Cell phone copies and research appointments were done at the discretion of individual staff and without any policies as to what constituted a request which should be accommodated. This meant that staff served a gatekeeping function much more than they did during our normal operations, as they had to make a decision about whether something was "sufficiently important" or timely to justify the added work of an appointment or snapshots. This was an uncomfortable position for staff to be in, and likely some of the people who did get more access did so because they were willing to push and make noise, rather than accepting when they were told that we were closed. Staff were aware of and commented on these issues.

Conversely, when administration encourages staff to take care of themselves, that sets a tone for the team, and the team in turn becomes more empathetic to each other's needs. As Meredith Farkas wrote in the recent article "Building Morale in a Pandemic: How to support library workers as whole people":

Supporting library workers as whole people and giving them opportunities to connect beyond their daily work can have a significant impact on morale and productivity. The time it takes to create and maintain structures like these is worth the investment for its impact on organizational culture and library worker well-being. (Farkas, 2021) 
As a prime example, Participant 12 from a large private institution described an administrative approach that seems to have had a positive impact on equity:

One other HUGE thing was that my staff all really pulled together. We all took turns in scanning, photocopying, page counts etc., including me. This meant that those who felt unsafe travelling in on the subway did not feel like they weren't pulling their weight - we really equitably divided the physical work from the organizational/communication work and it was really visible because everyone was involved in some aspect of it. As the head of the department, it was really important that people saw me doing the same thing. They knew I'd been in even earlier also (June and July) to move items out of people's offices, and to prepare the space so everyone really felt equal and that was probably the most important thing.

Racism in special collections. Special collections and rare book librarianship has experienced the same cultural shifts that are currently impacting our country and the world. In 2020-2021, we all witnessed racist murders by the police as well as a global pandemic that laid bare a host of inequities. The forces of racism, sexism, homophobia, ableism, and classism have been at work in our society for generations, but the shift in how we as a society acknowledge, understand, and address them has also led to discussions and changes in our profession.

Participant 3 from a small private institution wrote at length about how their institution has implemented changes to reading room accessibility in light of COVID-19 and as a way to combat racist policies:

The patron-centered language of our website revision from our time in renovation was vital to the way in which we crafted our public message about services during COVID19. We tried very hard to emphasize that the extra rules we were adding were not intended to discourage research, but were intended to keep everyone safe. We emphasized what was possible, not what was forbidden, and that we were always happy to talk with anyone about their research.

Further, in light of the racist murders of Black people by police and subsequent protests in summer 2020, we tried to consider specifically how the more restrictive policies we were now implementing might most disproportionately affect the very 
communities we were hoping our new policies would make more welcome. Limiting inperson access to campus (and thus to the library building and special collections) only to students, faculty, and staff means that that they have access to our collections in ways those residing in the majority-minority city we are near (and which our admissions team certainly uses as a recruitment tool) do not. We have in no way solved this issue, but it is something we continue to think about as we move deeper into our COVID service model and beyond it.

Racism also affected staff, especially in cases where administrators actively ignored racism as a factor in the workplace. According to Participant 15 from a large private institution:

Having administrators actually come on site or conduct listening sessions with staff working on site, or all staff to actually hear about health and safety concerns, as well as stress. We get a lot of messages about self-care and taking it easy but this is not evident in policy or in opportunities for feedback. This is especially stark in the whiteness of the messaging and fails to take into account the impact of the pandemic (and political climate) on staff of color and working class staff.

Participant 15 discussed structural inequities between staff members due to the effects of the legacy of segregation on their region's infrastructure. They reported major racial disparities, which only became more evident in the remote work environment. Black colleagues regularly experienced unreliable electricity or internet access after storms which made the burden of working from home greater.

\section{Positive outcomes}

While the renovation period was often extremely difficult, several participants reported being satisfied with renovated spaces that improve the user experience. Several participants remarked that renovations had improved accessibility and made their spaces more welcoming.

Participant 10 from a large public institution wrote about the positive improvements their renovation allowed. They moved their reading room from the basement to the first floor. 
Improvements include easier access and visibility, accessible furnishings, and more diversity represented in the artwork on display. Participant 21 from a small private institution wrote, "We have been working on prioritizing accessibility and universal design in our reading room in our temporary space and our new, renovated space should be even more accessible."

\section{Conclusion}

This article originates not from an administrative standpoint, but largely from people working full-time jobs on the front lines of library services, people who don't typically have decisionmaking power. While there are a number of articles about how archives and special collections libraries have addressed renovations and there is a burgeoning literature on responses to COVID19 , our aim was to provide a platform for those working in the archives and special collection field to safely voice their honest opinions about these sometimes fraught topics. In keeping with Hoelscher and Burke Calahan's idea that renovations (and other major disruptions) can present an opportunity to evolve from legacy practices that no longer make sense, the survey participants and their colleagues highlighted all they have done to progress when faced with challenging situations.

Progress is required, not just at the individual or institutional level, but for the wider professional community. The authors and participants frequently commented on their frustration at the dearth of scholarship available to serve as a guide to those undergoing major disruptions, especially renovations. Further documentation, conversation, and presentations that note realistic experiences are not just needed but wanted, in part to reduce the redundancy of replicated mental work and effort put into each and every plan for a disruption, but also to support the emotive feelings that are so often ignored by administration during times of instability. As Adler and Sloniowski write: 


\section{Participant 18 made a notable statement in their survey response "We're not selling something.}

These are patrons. It's a relationship. We're partners in helping them." This was echoed by Participant 29:

Considering we are still in this, I think we're still doing the best we can. We are committed to opening up the archives as much as we can as services and space are finished with construction. Overall, our comments and feedback has been appreciative toward our efforts to make services available as we can. The biggest lesson I'd say is letting people know that you are willing and want to work with them and make them a partner in working through the challenges that exist to get them what they need.

The authors would like to congratulate the hard-working respondents for all that they have done. So many of them responded that in spite of everything, they have managed to serve all or most of their users and satisfy most requests. This level of commitment and hard work is incredible and likely has gone unacknowledged. We are grateful for the candid, thoughtful, and observant responses provided by all. 


\section{Recommendations}

Note: Some recommendations were explicitly stated by respondents, while others were inferred by authors. Authors categorized and noted similar topics and expanded upon them below. These were the takeaways that helped people overcome disruption and related challenges during major disruptions. Lessons learned from renovation that were applicable in the pandemic and vice versa.

\section{Staffing}

- Hire a project manager to be responsible for a renovation. Expecting staff members to take over this work often goes beyond their capacities and is more often than not, not financially compensated. Staff who take on further responsibilities for the renovation are not allowed or encouraged to pause their other work and often wind up burnt out.

- Participant 6: "Art Museum Director advised us early on to hire someone to coordinate everything and we did not get to do that. That would have been so helpful."

- Participant 28: "We had a wonderful experience with the roof and skylight replacement because the contractor assigned us a project liaison who listened to us and was our advocate. He was willing to listen to our needs and why, and valued our expertise. We had a dreadful experience with the HVAC contractor because there was no liaison, and our needs and expertise were dismissed constantly." 


\section{Communication}

- Recognize the expertise you have and use that while advocating for the collection materials.

- Build good relationships with professional allies (e.g. facilities workers and managers, construction staff, architect and staff).

- Gather data in order to support your viewpoints and share with the appropriate groups.

- Alert your community to the coming disruption much earlier than you think you should. Be upfront and transparent about as much information as you can including the limitations to users and how they may prioritize their own work.

- Routing as much communication with researchers to email format (versus in-person, phone, chat, etc.).

- Place the informative notices on your

- Website (e.g. in a banner, on a disruption-specific page, on potential other pages)

- Voicemail

- Email signatures and out of office responses

- Reference email boiler plate language and email signatures

- The main library website

- Be explicitly clear about design requests and requirements when discussing renovation plans and know that you may have to be firm in your requests in order to have them be respected (e.g. movable, light tables; shelving that fits hollinger boxes; appropriate lighting; outlets in helpful places, etc.). 


\section{Policies and Procedures}

- Be flexible and open to change (e.g. suspending fees, closing services, moving to appointments only, etc.).

- Complete contingency planning for all types of disruptions well in advance of them being a reality.

- Address lingering issues in all policies and procedures as much as possible prior to a disruption (e.g. emergency, natural disaster, and preservation policies).

- "I cannot stress enough how important it is not to be overly optimistic about the impact of construction on both collections and services."

- Close your services!

- While all of our work is done in service of the public, attempting to maintain services in advance of, during, and in the wake of a major disruption (especially a renovation) was discussed as being wildly unfair and unnecessarily chaotic for staff. In all cases, those who were not able to close their services overemphasized how overtaxed, stressed, and upsetting this turned out to be.

- Participant 28: "Suspending services to allow staff greatest opportunity to focus on the disruption which cuts down on the time it then takes for the disruption to be completed."

- Suspend and waive fees for researchers.

- When you unpack, "know that you will never go back and rearrange...Take the extra time up front and give yourself extra space”. 


\section{Digitization}

- Digitize the most used collections in advance of a renovation to help mitigate the disruptive effect on researchers.

- Be clear about how much labor, finances, and time it takes to digitize materials.

- Don't assume that in-person visits are the best, most appropriate method of researching. As Participant 27 stated, "We have always strived to ensure that researchers only physically need to visit our reading room as a last resort. [W]e know researchers ... don't need the total research experience involved in visiting the reading room in-person. I think that [visiting in person] is an outmoded way of conceptualizing libraries and archives, and adds to a 'mystique' or 'aura' surrounding research that intimidates potential researchers and drives them away."

\section{Declaration of Interest}

No potential competing interest was reported by the authors

\section{Data availability statement}

Data available within the article or its supplementary materials

\section{References}

Adler, K., \& Sloniowski, L. (2020). Introduction. Library Trends, 68(3), 369-378. https://doi.org/10.1353/lib.2020.0006 
Blackson, M., \& Stringfellow, J. (2021). It's raining in the archives: Practical lessons and impactful results from moving an academic archives. Journal of Western Archives, 12(1). https://digitalcommons.usu.edu/westernarchives/vol12/iss1/5

Caswell, M., \& Cifor, M. (2016). From human rights to feminist ethics: Radical empathy in the archives. Archivaria, 81(1), 23-43.

Chapman, J., \& Hammeke, E. (2020). Black Scholarship Spaces in Libraries-Ivy Plus and TRLN Summary. https://docs.google.com/document/u/1/d/1S65ppGLn5dTdZirizIHH30DDx6uqgXssCJ31wY

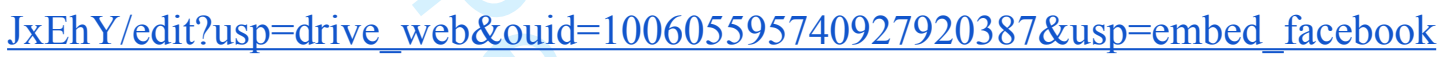

Ettarh, F. (2018, January 10). Vocational Awe and Librarianship: The Lies We Tell Ourselves [In the Library with the Lead Pipe]. https://www.inthelibrarywiththeleadpipe.org/2018/vocational-awe/

Farkas, M. (2021, March 1). Building morale in a pandemic. American Libraries Magazine. https://americanlibrariesmagazine.org/?p=122054

Glusker, A., Dyess, B., Emmelhainz, C., \& Estrada, N. (2021). Library staff morale in the academic hierarchy. https://escholarship.org/uc/item/30790731

Hackbart-Dean, P., Agne, L., \& Mosbo, J. (2010). History on the move: Relocating special collections and archives. Provenance: The Journal of the Society of Georgia Archivists, 28, $31-57$.

Hatcher, R., \& Sciarini, N. (2017). To Close, or Not to Close - That is the Question. IFLA WLIC 2017 WROCLAW. http://library.ifla.org/1673/ 
Healey, E., \& Nykanen, M. (2016). Channeling Janus: Past, present, and future in the RBMS membership survey. RBM: A Journal of Rare Books, Manuscripts, and Cultural Heritage, 17(1), 53-81. https://doi.org/10.5860/rbm.17.1.461

Hoelscher, C., \& Burke Cahalan, S. (2017). Rethinking special collections moves as opportunities, not obstacles. RBM: A Journal of Rare Books, Manuscripts, \& Cultural Heritage, 18(2), 123-132. https://doi.org/10.5860/rbm.18.2.123

Kendrick, K. D. (2017). The low morale experience of academic librarians: A phenomenological study. Journal of Library Administration, 57(8), 846-878. https://doi.org/10.1080/01930826.2017.1368325

Kendrick, K. D. (2020). The public librarian low-morale experience: A qualitative study. Partnership: The Canadian Journal of Library and Information Practice and Research, 15(2), 1-32. https://doi.org/10.21083/partnership.v15i2.5932

Kezar, A., \& Lester, J. (2010). Breaking the barriers of essentialism in leadership research: Positionality as a promising approach. Feminist Formations, 22(1), 163-185. https://doi.org/10.1353/nwsa.0.0121

Monheim, A., Casey, C. M., Lally, A., Rodgers, C., Jenner, A., Bolcer, J. D., Palin, H. L., Dominick, E., Kroupa, S., \& Oberg, L. (2020). Resilience and flexibility: Adaptive responses to the COVID-19 shutdown at the University of Washington Libraries Special Collections. Pacific Northwest Library Association (PNLA) Quarterly, PNLAQ Special Issue 2020, 36-52.

Morrow, M. F. (1990). Moving an archives. The American Archivist, 53(3), 420-431.

Pacifico, M. F., \& Wilsted, T. P. (2009). Archival and Special Collections Facilities: Guidelines for Archivists, Librarians, Architects, and Engineers | ALA Store. SAA. 


\section{https://www.alastore.ala.org/content/archival-and-special-collections-facilities-guidelines-} archivists-librarians-architects-and

Rossman, J. J. (2013). Build it and s/he will come: A reflection on five years in a purpose-built special collections space. RBM: A Journal of Rare Books, Manuscripts, \& Cultural Heritage, 14(2), 111-120. https://doi.org/10.5860/rbm.14.2.405

Smith, D. (2020). Vocational melancholy. Library Trends, 68(3), 450-481. https://doi.org/10.1353/lib.2020.0001

Trivette, K. J. (2017). Historical holdings and new dimensions: The Fashion Institute of Technology-SUNY Library Unit of Special Collections and College Archives. Art Libraries Journal, 42(3), 140-147. https://doi.org/10.1017/alj.2017.20

Warren, K. E., \& Scoulas, J. M. (2021). Excessive workload in special collections public services librarianship: Challenges, feelings, and impact. Journal of Library Administration, 61(3), 312-331. https://doi.org/10.1080/01930826.2021.1883369

Wilsted, T. P. (2012). Renovating special collections facilities. Journal of Library Administration, 52(3-4), 321-331. https://doi.org/10.1080/01930826.2012.684530

\section{Supplemental Material}

\section{Appendix A: Survey questions}

Overcoming Disruption in Special Collections Public Services

1. General Interview Questions

a. Did you have to close your library at any point during your renovation (or other disruption to your library space)?

i. If you were closed, what did this entail? What services were unavailable or significantly changed?

ii. Were some services still provided? 
iii. If so, what services?

b. If you did not have to close, please describe your experience.

2. Reading room management

a. What changes did you implement to your reading room services during renovation (or other disruption to your library space)?

b. Did you change the rules of access to the reading room? (e.g. requiring appointments. What may the challenges and benefits of reading room appointments have been? What was the staff time needed to manage appointments like?)

c. How did you manage patron expectations if services changed?

d. Did you retain any of those changes after your building resumed "normal" operation?

3. Reference email management

a. How did you manage reference during your renovation (or other disruption to your library space)?

b. Did your service level change during the move of collections (if collections moved)?

c. How did you manage reference if your building/department was completely closed during renovation (or other disruption to your library space)?

d. How did reference change upon reopening? What lessons did your team learn?

4. Services during COVID-19

a. How have you handled remote reference during the pandemic?

b. Did you carry forward any lessons learned regarding reference services from renovation reference (or reference during other disruption to your library space) into pandemic reference?

c. Did changes to reading room accessibility during your renovation (or other disruption to your library space) have any implications or provide any inspiration for reading room accessibility during the pandemic?

d. Have you decided on any permanent changes to your services based on your experiences during the pandemic?

5. Strain on staff and patrons and how to manage

a. How did your library administration handle making special collections and special collections services available during COVID-19?

b. What was expected of staff in terms of who was required to go to work and who could work from home?

c. What challenges were faced by staff when providing the above services while in either situation?

d. Reflect upon the efficacy of the services provided.

e. Reflect upon what changes could have been made for better efficacy.

Wrap-up meeting questions for participants 
1. What is the size of your special collections/archives staff? How many staff have instruction duties? Public Services duties?

2. What is the size of your collections in special collections/archives?

3. Do you have any photos (before/after, issues during reno, disaster, etc.) you'd be willing to share for our article?

4. Are there any questions you expected to see on the survey that we didn't ask?

Appendix B: Coding categories

\begin{tabular}{|l|l|}
\hline Broad theme & Definition \\
\hline Administration & $\begin{array}{l}\text { Discusses administrators and how they interacted with all other } \\
\text { stakeholders during interruption/renovation. }\end{array}$ \\
\hline Communication: internal & $\begin{array}{l}\text { Communication among staff, staff and contractors, staff and } \\
\text { architects, etc. This includes discussions about current policies and } \\
\text { procedures or plans to change them. }\end{array}$ \\
\hline Communication: external & $\begin{array}{l}\text { Communication with researchers, library users, constituency, } \\
\text { community. Also includes reference work. }\end{array}$ \\
\hline Equity & $\begin{array}{l}\text { Issues of equity and/or inequality at a structural or interpersonal } \\
\text { level. Can also include issues of staff safety. }\end{array}$ \\
\hline Funding & $\begin{array}{l}\text { Discussion of money or the lack thereof for staff, supplies, or } \\
\text { projects }\end{array}$ \\
\hline Morale & Morale or mental health issues among staff or patrons \\
\hline Random & $\begin{array}{l}\text { Random or unexpected challenges, or helpful surprises/windfalls. } \\
\text { The random category is for events other than participant's major } \\
\text { renovation/disruption or pandemic response. }\end{array}$ \\
\hline Recommendations & $\begin{array}{l}\text { Helpful points for those embarking on a renovation and/or } \\
\text { continuing to offer services. }\end{array}$ \\
\hline Security measures that are in place or changed; safety of \\
collections.
\end{tabular}




\begin{tabular}{|l|l|}
\hline Technology & $\begin{array}{l}\text { Anything having to do with the necessary technologies to facilitate } \\
\text { work }\end{array}$ \\
\hline Time & $\begin{array}{l}\text { Timeline of move, interruption, or closure; Time-related } \\
\text { challenges. }\end{array}$ \\
\hline
\end{tabular}

